\title{
O Federalismo e o Internacionalismo na Comuna de Paris
}

Felipe Corrêa Pedro

Mestrando em Participação Política e Mudança Social (Universidade de SãoPaulo)

felcor@usp.br

SAMIS, Alexandre. Negras Tormentas: o federalismo e o internacionalismo na Comuna de Paris. São Paulo: Hedra, 2011, 368 p.

Originais recebidos em: 14/09/2011

Aceito para publicação em: 16/09/2011

Negras Tormentas, de Alexandre Samis - doutor em História pela Universidade Federal Fluminense e autor dos livros Clevelândia: anarquismo, sindicalismo $e$ repressão política no Brasil (Imaginário/Achiamé, 2002) e Minha Pátria é o Mundo Inteiro: Neno Vasco, o anarquismo e o sindicalismo revolucionário em dois mundos (Letra Livre, 2009) - constitui um marco nos estudos históricos acerca da Comuna de Paris. É tamanho o rigor da obra, no tratamento do objeto, que o francês René Berthier prefaciador do livro e especialista nos clássicos do socialismo - surpreendeu-se: "o leitor europeu como eu encontra-se confrontado com uma abordagem à qual não está acostumado"; a abordagem de um latino-americano "que nos proporciona suas reflexões sobre eventos históricos que tínhamos o costume de considerar como estritamente franceses, ou europeus". (p. 13) Wallace dos Santos Moraes, professor e pesquisador, complementa: "enfim, o livro, hoje, é a principal referência sobre o estudo da Comuna de Paris já publicado no país". Tais comentários certamente são motivados pelo amplo conjunto de informações e argumentos apresentados no livro, além das teses fundamentais desenvolvidas pelo autor.

Contrapondo a difundida tese de que a Comuna teria sido tão-somente uma reação patriótica do povo francês contra o armistício assinado em relação ao conflito 
com a Prússia, Samis a define como um episódio de auto-instituição da classe trabalhadora, com raízes no federalismo desenvolvido no seio do movimento popular francês e da Associação Internacional dos Trabalhadores (AIT), a qual também foi responsável por impulsionar o internacionalismo das lutas sociais.

A comprovação dessa genealogia da Comuna fundamenta a estrutura da obra, que se divide em três grandes partes. A primeira, sobre a França no contexto de 1848, trata da crise, da revolução e das Jornadas de Junho, dando destaque às lutas dos trabalhadores e ao pensamento de Proudhon. A segunda, sobre a AIT, discute amplamente essa experiência dos trabalhadores que ficou conhecida como Primeira Internacional, passando por seus congressos e evidenciando seus principais debates. A terceira, mais longa e detalhada, tem como objeto central a Comuna de Paris e enfatiza a luta e o novo poder estabelecidos pelos trabalhadores nos bairros parisienses, além de sua representação no governo communard. Inicia com a conjuntura anterior ao março de 1871, tratando do desenvolvimento da AIT na França, da Guerra Franco-Prussiana e da Comuna de Lyon, e vai até os confrontos dos rebeldes com as forças da ordem e a sangrenta repressão que se seguiu, passando pelo amplo conjunto de experiências, que envolveram aspectos trabalhistas, decisórios, militares, educacionais, artísticos, de organização de gênero, entre outros. Na conclusão, o autor evidencia suas teses fundamentais, as quais serão substanciadas a seguir.

Pelo menos desde os anos 1820, a classe trabalhadora francesa acumulou significativamente por razão da fundação de sociedades de socorros mútuos, de associações econômicas e da realização de greves; um repertório tal, que demonstrava tanto sua capacidade como sua força. O elemento central presente na classe trabalhadora francesa - impulsionado pelos mutualistas desde 1828, apreendido e teorizado por Proudhon, e que, como demonstra Samis, terá um impacto de primeira ordem na Comuna de Paris - é o federalismo. As práticas federalistas implicaram, desde seu início, o fortalecimento das associações de base dos trabalhadores e, por meio da autonomia, sua organização em torno das necessidades econômicas; avançaram com o passar do tempo, chegando a propor a superação do Estado e do capitalismo por meios revolucionários e o estabelecimento, “de baixo para cima", do socialismo.

Proudhon [...] via na autonomia econômica da classe operária, só possível através do controle das unidades produtivas (fábricas, oficinas etc.), e na emancipação política, através do federalismo, portanto contra o Estado, as formas mais seguras para se atingir o socialismo. Como desdobramento deste seu pensamento, rejeitava igualmente os modelos derivados do jacobinismo primitivo, a centralização política na forma do Estado e a subordinação 
econômica levada a efeito pelo mesmo, ainda que sob o argumento da 'soberania popular'. Tal concepção, denunciava, seria a revolução 'de cima para baixo'. Ele defendia a revolução 'de baixo para cima'. [...] Para Proudhon, o federalismo era a expressão orgânica possível da gestão operária, seu corolário político, a ossatura que permitiria o fluxo de trocas e relações na sociedade cujo estatuto da propriedade tornar-se-ia coletivo por força das transformações operadas pelos trabalhadores. [...] O federalismo de Proudhon era, assim pensado, indissociável da luta de classes e da derrubada do sistema capitalista. (p. 71-72; 93-94).

Essa relação dialética entre as práticas da classe trabalhadora francesa e sua teorização na obra de Proudhon permitiu que, em 1864, setores do operariado francês, influenciados amplamente pelo federalismo, juntamente com setores do operariado britânico, fundassem a AIT em Londres. Por meio de seu desenvolvimento, explicitado mais evidentemente nas discussões congressuais - Genebra (1866), Lausanne (1867), Bruxelas (1868) e Basiléia (1869) -, Samis demonstra como a influência do setor federalista, que incorporava também o internacionalismo, preponderou como ideologia hegemônica da associação, num primeiro momento por meio do mutualismo, e depois pelo coletivismo, difundido, entre outros, por Mikhail Bakunin.

Por meio de uma atenta discussão dos congressos da AIT, Samis evidencia esse desenvolvimento, marcado pela radicalização e pelo crescimento orgânico da associação, que não se deu sem intensas disputas entre as correntes; tanto entre federalistas e centralistas, como dentro do próprio campo federalista. Em linhas gerais, pode-se dizer que nos dois primeiros congressos (Genebra e Lausanne) preponderaram as propostas federalistas, impulsionadas pelos mutualistas, que defendiam a estruturação da AIT em seções federadas, as quais deveriam se articular em bureaux, compostos de delegados de base com mandatos revogáveis; em termos estratégicos, esses congressos optaram pela promoção das cooperativas de produção, consumo e crédito, juntamente com o ensino laico, científico e profissional. Nos dois congressos seguintes (Bruxelas e Basiléia) continuou a preponderância dos federalistas; entretanto, foram os coletivistas, e não os mutualistas, que direcionaram a maioria das decisões. Incentiva-se a criação e o fortalecimento das associações de resistência, as greves e as lutas pela redução das jornadas de trabalho; assume-se uma luta aberta contra o capitalismo tendo por objetivo o fim das heranças e estabelecimento da propriedade coletiva e do socialismo, que deveria ter por base as práticas federalistas já existentes. Segundo Samis, as decisões congressuais da AIT imprimiram-lhe, ao longo dos anos, uma forma antiautoritária, federalista: "tanto o mutualismo quanto o coletivismo constituíam-se em formas 
históricas específicas de uma mesma tradição antiautoritária e federalista presente no movimento operário francês”. (p. 150)

Em 1871, a Comuna de Paris incorpora, como demonstra Samis, todo um repertório da classe trabalhadora francesa que se consolida nas deliberações que optam pela abolição da divisão clássica entre os três poderes, o estabelecimento de um tipo de "poder popular" federalista - emanado das bases trabalhadoras que se encontravam nos bairros e articulado por uma estrutura federada de delegações políticas revogáveis - e a organização de comissões executivas: Guerra, Finanças, Segurança Geral, Ensino, Subsistência, Justiça, Trabalho e Trocas, Relações Exteriores e Serviços Públicos. Dentre as inúmeras realizações da Comuna, que beneficiaram a classe trabalhadora, destacam-se: a substituição do exército regular pelas milícias cidadãs, a separação entre Igreja e Estado, a abolição dos cultos religiosos, medidas relativas ao trabalho e local de moradia (reduções de jornada, ajustes e equiparações salariais, fim das multas, entrega de oficinas e prédios abandonados aos trabalhadores), concessão de crédito com juros reduzidos, moratória para dívidas, devolução de itens penhorados, gratuidade das escolas públicas, ensino laico e politécnico, reorganização jurídica, confisco de bens de raiz, protagonismo de mulheres e artistas.

Esse novo poder estabelecido pela classe trabalhadora francesa a partir dos bairros - o qual possibilitou as amplas realizações da Comuna de Paris em seus breves 72 dias - evidenciava uma democracia radicalizada, construída pelo próprio povo, sem lugar para a burocracia. De acordo com Samis:

\begin{abstract}
A experiência parisiense oportunizou o vislumbre de uma nova forma de ordenamento político da sociedade. A delegação, que possibilitava a revogação dos mandatos, a circunscrição do voto aos bairros, assim como a permanente interferência dos trabalhadores-eleitores nos assuntos cotidianos da administração pública, formas de instituir pela prática uma outra cultura política, tinham deixado evidências de que o sufrágio universal era, no mínimo, uma instituição acanhada diante das exigências da democracia popular. [...] O novo poder, fundamentado nos mecanismos democráticos radicais, entre os quais se destaca a revogabilidade da titularidade delegativa, além da instituição do poder político direto nos arrondissements, mostrou-se hostil às permanências burocráticas. (p. 351; 354).
\end{abstract}

A tese sustentada pelo autor em relação à forma desse novo poder, constituído a partir de linhas claramente federalistas, é que, apesar da maior força política no seio da Comuna ser a dos jacobinos e blanquistas, os socialistas revolucionários - certamente influenciados pela AIT, que naquele momento possuía 35 seções na França, e dentre os quais se destacava Eugène Varlin -, muito em função do referido acúmulo da classe trabalhadora francesa, viram na Comuna suas posições espalharem-se bem mais 
generalizadamente que as dos adversários centralistas. Samis enfatiza, citando Bakunin, que, na Comuna de Paris, "a maioria "não era propriamente socialista", mas "acabou por ser arrastada 'pela força irresistível das coisas"”; "restou aos jacobinos e blanquistas [...] aceitar a radicalização do processo rumo ao socialismo". (p. 340)

Esse processo, em que o conjunto da classe e seu repertório de lutas arrastavam posições divergentes e as conciliavam em torno de um projeto revolucionário claramente federalista e internacionalista, envolveu, inclusive, Karl Marx. Conforme sustenta Samis, em outra tese relevante de Negras Tormentas, não só Marx e sua obra não tiveram qualquer influência sobre a Comuna, como A Guerra Civil na França, muito mais do que um elo entre o passado e o futuro das teorias do alemão, caracterizou-se como uma concessão em relação à realidade dos fatos: "não há dúvida que a Comuna acabou por tornar-se um ponto importante de inflexão no pensamento de Marx". (p. 349) Ainda que Marx fizesse parte do Conselho Geral da AIT, e que por isso tivesse a função de corresponder-se com as seções - dentre elas as francesas -, não se pode, segundo o autor, associar mecanicamente esses contatos com a influência marxiana na Comuna. A influência da AIT se deu, segundo Samis, muito mais pelo setor federalista, hegemônico até 1871, do que pelo setor centralista, do qual Marx era um dos principais representantes. Enfim, essa realidade dos fatos constituída pela Comuna colocaria do mesmo lado Marx e Bakunin, maiores representantes do comunismo e do coletivismo: "A torrente dos acontecimentos, sua materialidade, arrastou no mesmo torvelinho os dois pólos, o coletivista e o comunista, para um ponto comum. Ainda que com algumas contradições, as análises não apresentavam antagonismo.” (p. 350) A Comuna, assim, fez convergir a admiração e o respeito de todo o campo socialista revolucionário, sendo posteriormente reivindicada por praticamente todas as suas correntes.

Contestando outras teses difundidas sobre a Comuna de Paris que a identificam como "a última revolução plebéia" ou "a primeira revolução proletária", Samis afirma que "a Comuna foi uma experiência de auto-instituição, um evento que possui autonomia, não apenas por sua ousadia, mas por suas singularidades. [...] um marco que não se presta a transformar-se em linha de chegada ou partida, mas que definiu nas suas práticas concretas os elementos fundamentais da democracia popular no século XIX." (p. 357-359)

A Comuna, constata o autor, não pode ser analisada como uma continuidade dos episódios revolucionários que tomaram corpo durante a Revolução Francesa, ou nas Em Debat: Rev. Dig., ISSNe 1980-3532, Florianópolis, n. 6, p. 252-257, jul-dez, 2011. 
revoluções de 1830 e 1848 na França. Também não pode ser considerada somente como processo inicial das revoluções proletárias do século XX. O histórico dos antecedentes da Comuna, sua herança das práticas que prevaleceram no seio da classe trabalhadora francesa e o desenvolvimento das revoluções posteriores permitem colocá-la como um elo constituído a partir de teorias e práticas passadas, que exerceria significativas influências em teorias e práticas futuras. Por meio do conceito de auto-instituição da classe de Castoriadis, Samis demonstra que a Comuna constituiu um processo revolucionário que colocou a classe trabalhadora no timão da luta de classes, atuando conscientemente em benefício próprio e ameaçando as estruturas de dominação da sociedade francesa, a partir da construção de um novo modelo de poder, forjado pelo federalismo - uma verdadeira “democracia popular".

Negras Tormentas constitui, enfim, uma referência histórica central para os estudos sobre a Comuna de Paris. Destaca-se ainda a metodologia utilizada por Samis, que insiste em uma história construída de baixo para cima. É esse motivo que afasta o livro das visões históricas construídas em sentido contrário, que fazem a leitura, no caso da Comuna, a partir daqueles que teorizaram sobre ela ou mesmo da instância política estabelecida como o governo communard. Analisar esse episódio de cima para baixo seria, nos dizeres do próprio autor, roubar da Comuna aquilo que ela tem de mais brilhante. O livro certamente contribuirá para que se aprofundem os estudos históricos e sociológicos desse episódio tão relevante da luta dos trabalhadores franceses no século XIX. 